\title{
Téoros
}

Revue de recherche en tourisme

\section{La gestion touristique : des modèles à construire}

\section{Jean Stafford}

Volume 5, numéro 3, novembre 1986

La gestion touristique : les nouvelles technologies

URI : https://id.erudit.org/iderudit/1080530ar

DOI : https://doi.org/10.7202/1080530ar

Aller au sommaire du numéro

Éditeur(s)

Université du Québec à Montréal

ISSN

0712-8657 (imprimé)

1923-2705 (numérique)

Découvrir la revue

Citer ce document

Stafford, J. (1986). La gestion touristique : des modèles à construire. Téoros, 5(3), 1-1. https://doi.org/10.7202/1080530ar d'utilisation que vous pouvez consulter en ligne.

https://apropos.erudit.org/fr/usagers/politique-dutilisation/ 


\section{Présentation}

\section{La gestion touristique: des modèles à construire}

// semble bien, pour utiliser une expression d'Alain Flautre, "qu'ill n'existe pas de modèle de gestion d'entreprise touristique". Le secteur de la grande hotellerie et de la restauration mis a part, nous pouvons penser que la gestion touristique n'existe pas; elle est à faire, à inventer, a construirel Cette nouvelle discipline s'elabore, tant bien que mal, å travers les obstacles et les difficultés propres au domaine touristique.

La première täche de cette discipline en gestation est de definir une typologie des entreprises qui tiennent compte des elements spécifiques et des particularismes propres a lentreprise touristique. La deuxième tâche est de construire des modeles de gestion compatibles avec les structures actuelles de l'industrie touristique québécoise. Celle-cl, tous les experts sont d'accord, fait face à des problemes lancinants au plan de /organisation, de la gestion financiere et de la gestion des ressources humaines.

La troisième tâche est d'élaborer des systemes de prévision simples et efficaces qui permettent de mieux naviguer dans un milieu économique bouleversé, en crise. perturbé par des fleaux cycliques (des cataclysmes naturels au terrorismel auxquels /'entreprise touristique est très sensible. Cette fragilitế aux phénomènes exogènes peut être combattue, et c'est le thème de ce numero de Téoros, par des modes de gestion diversifiés et souples qui renforcent les capacites de résistance des petites et moyennes entreprises face a la conjoncture.

Les nouvelles technologies, plusieurs articles abordent icice sujet, vont amener une plus grande maniabilité dans la gestion touristique, elles favoriseront aussi un meilleur traitement de linformation. Les informations et messages seront transmis et connus d'une façon quasi-instantanée ce qui permettra une adaptation plus rapide aux besoins du marché touristique.

Enfin, on peut esperer, qu'à plus long terme, la gestion touristique pourra s'inscrire dans ce que Michel Godet appelle: "Ia planification stratégique" "w1); celle-ci se situe dans le prolongement de la prévision et de la gestion. $\mathrm{La}$ planification stratégique englobe autant le court terme que le long terme, le positionnement de l'entreprise que la programmation des actions et l'affectation des movens. Dans les tempêtes économiques et politiques qui s'elèvent, ces différents modeles ne seront pas de trop. $f$

Jean Stafford

(1) GODET, M., Prospective ot planification stratégique, Economica, Paris, 1965.

\section{Des changements à Téoros}

Téoros entre dans whe phase d'expansion at a de nombreux projets de développement. notamment la parution d'ouvrages specialisés en tourisme. Pour relever les nouvedux defis. des changements administratis ont été apportés. Le poste de directewr et de ródac. teur en chef est scindé en deux: Jean Stafford, économiste, professeur au Départemont d'eludes urbaines de IUQAM, assumera dorenavant la fonction de rédacteur en chef de la revue et Louis Jolin, comme directeur, a la rasponsabilité administrative de la revue et des projets de developpement.

Deux nouveaux membres font partie du comite de direction et de rédaction: II s'agh de Roger Nadeau, geographe a r Universite de Sherbrooke et de Gerald Pomerieau, diplôme du Baccalaureat en gestion et intervention towistiques et directeur du marketing d la Librainie Ulysse.

Le comité est aussi composé de Mare Laplante, professeur au Département d'études urbahes (UOAM) de Marcel Samson. professeur-chercheur a I'INRS-Urbanisation. de Normand Cazelais, chroniqueur en tourisme et chargé de cours au Departement de geographie de I'UOAM, de Marie-Claude Car. dh, Lowise Tremblay et Andrée Lamontagne. etudiantes en gestion et infervention touristiques et enfin de Pierre Bellerose, assistant de recherche a IUOAM. Plerne Bellerose coordomne actuellement une petite équipe de travail. composée d'Andrée Lamontagne et de Sylvie Boudreau, quijette les bases de developpement futur de Teoros lrecherche commercialo, outils promotionnals, etc).
Augmentation des prix

Pour faire face a la hausse constante des couts de production, auX ameliorations qualitatives apportées a la revue (nouvelles chroniques, nouvele prisentation/, les prix seront légèrement augmentës a compter du vol. 6 (1987).

1 abomement reguler passera a 10 s. rabonnement étudiant a 85 et fabonnement "autres pays" a 75s. Le numéro se vendra, en 1987. 4 s.

Nous crovons que, malgré ces augmentations, la revue Téoros neste accessible. $f$

Louis Jolin

Directeur 